\title{
Growing up in a Material World: Age Differences in Materialism in Children and Adolescents
}

\author{
LAN NGUYEN CHAPLIN \\ DEBORAH ROEDDER JOHN*
}

\begin{abstract}
We examine age differences in materialism with children and adolescents 8-18 years old. In study 1 , we find materialism increases from middle childhood to early adolescence and declines from early to late adolescence. Further, we find that age differences are mediated by changes in self-esteem occurring from middle childhood through adolescence. In study 2, we prime self-esteem to obtain further evidence of a causal link between self-esteem and materialism. As expected, we find that inducing high self-esteem decreases expressions of materialism. Inducing high self-esteem reduces materialism among adolescents so dramatically that age differences in materialism disappear.
\end{abstract}

Contemporary American tweens and teens have emerged as the most brand-oriented, consumer-involved, and materialistic generation in history. And they top the list globally. . . . More children here than anywhere else believe that their clothes and brands describe who they are and define their social status. (Schor 2004, 13)

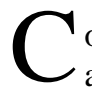
oncerns over the rising level of materialism in children and adolescents are increasing among parents, educators, and social scientists. In a recent national survey, 95\% of adults say that children are too focused on buying and consuming things, and almost $80 \%$ agree that limits should

*Lan Nguyen Chaplin is assistant professor of marketing, University of Illinois at Urbana-Champaign, School of Business Administration, 1206 S. Sixth St., 140B Wohlers Hall, Champaign, IL 61820 (nguyenl@ cba.uiuc.edu). Deborah Roedder John is Curtis L. Carlson Chair and professor of marketing, Carlson School of Management, University of Minnesota, 321 19th Avenue South, Minneapolis, MN 55455 (djohn@ csom.umn.edu). Correspondence: Lan Nguyen Chaplin. The authors acknowledge guidance provided by first author's dissertation committee (Michael Houston, Mark Ritson, Marti Gonzales) as well as by the JCR editor, associate editor, and reviewers. The authors thank the staff, parents, and students of the St. Paul and Urbana-Champaign area recreation centers for their participation. Special thanks go to our nieces, nephews, and neighbors who served as pretest participants. This research was funded by an ACR Sheth Dissertation Proposal Award received by the first author and research support from the University of Illinois and the Carlson School of Management at the University of Minnesota.

John Deighton served as editor and Laura Peracchio served as associate editor for this article.

Electronically published June 12, 2007 be placed on advertising to children (Center for a New American Dream 2004). In response, parents are joining organizations such as Commercial Alert and Center for a New American Dream, which advocate reducing the commercialization of American culture. Educators have responded by banning corporate donations of school materials and equipment that feature brand advertising (Seyfer 1999). Social scientists have responded with a burst of recent books that decry materialism among young consumers and criticize marketing's role in the development of materialistic values (Kasser 2002; Linn 2004; Schor 2004).

Despite these concerns, we know relatively little about how materialistic values develop in childhood and adolescence. Materialism has long been of interest to consumer researchers, but research has centered on adult consumers, not on children or teens. A small flurry of research appeared in the 1970s that found materialism in adolescents to be correlated with factors such as ineffective family communication patterns, greater peer communication, and higher levels of television viewing (Churchill and Moschis 1979; Moore and Moschis 1981; Moschis and Churchill 1978; Moschis and Moore 1979). Since then, only a handful of consumer behavior articles on the topic have appeared, finding higher levels of materialism in young consumers with materialistic parents (Goldberg et al. 2003), disrupted families (Rindfleisch, Burroughs, and Denton 1997; Roberts, Tanner, and Manolis 2005), less affluent households (Goldberg et al. 2003), and greater susceptibility to influence from peers and marketing promotions (Achenreiner 1997; Goldberg et al. 2003).

Of particular note is the absence of research examining 
how materialism develops in childhood and adolescence. Most observers believe that children begin to exhibit materialistic orientations around middle to late childhood, often referred to as the tween years, from 8 to 12 years of age. Books and articles in the popular press describe children as becoming brand conscious during this time, requesting and flaunting the brands that their peers deem popular (Lindstrom 2003). In fact, many observers link the emergence of materialism to peer influence, which becomes the primary source of identification and acceptance for children during the tween years (Kantrowitz and Wingert 1999; Siegel, Coffey, and Livingston 2001). Also implicated are marketing activities that target tweens, which increase exposure to brands and fuel the desire to obtain material goods (Quart 2003; Schor 2004).

Surprisingly, there is little academic research to support these contentions. Although the idea that materialism develops at some time between infancy and adulthood has merit, there is an absence of empirical research showing the existence of age differences during childhood or adolescence. Prior work has focused on factors other than age that influence materialism, involving samples of children or adolescents within narrow age ranges. To our knowledge, only two studies exist with a wide enough age range to detect age differences, and the results are far from unequivocal. One finds a linear trend in materialism that increases in 7-16-year-olds (Achenreiner 1997), whereas a second finds no age differences among 9-11- versus 12-14-year-olds (Goldberg et al. 2003). Needed is a closer examination of age differences to identify antecedents of materialism that vary as a function of age, thus providing a theoretical explanation for why materialism would vary from childhood through adolescence.

In this article, we focus on self-esteem as an explanation for age differences in materialism. Specifically, we propose that age differences are driven, in large part, by changes in self-esteem that occur from middle childhood through adolescence. Research from child psychology documents that self-esteem drops dramatically around ages 12-13 and then rebounds with the approach of late adolescence (ages 16-18). Given the strong connection between self-esteem and materialism (Kasser 2002), we believe that age-related patterns in self-esteem give rise to age differences in materialism. Because self-esteem exhibits a curvilinear trend, decreasing from middle childhood to early adolescence and increasing from early to late adolescence, we predict that materialism will exhibit a curvilinear pattern as well. Instead of increasing with age, as most observers suggest, we propose that materialism increases from middle childhood to early adolescence and then decreases from early to late adolescence.

We examine these propositions across two studies with children and adolescents ages 8-18. In the first study, we test our predictions in the context of a survey including measures of self-esteem and materialism. The results confirm a curvilinear pattern of age differences as well as provide evidence for the link between self-esteem and mate- rialistic orientations. In the second study, we examine the causal link between self-esteem and materialism in an experimental context by priming high self-esteem in a sample of 8-18-year-olds. Comparing levels of materialism in this group with those of a control group, we find that priming high self-esteem has the expected effect of reducing materialistic tendencies, especially among early and late adolescents.

In doing so, we contribute to the evolving debate on materialism among young consumers. First, we find that materialism develops in childhood through adolescence in a unique nonlinear fashion. Second, we provide evidence that these developmental changes are due, in large part, to age-related changes in self-esteem. Not only does this contribute to an understanding of why materialistic tendencies vary with age, but it is also the beginning of a conceptual framework to explain how materialism develops in children and adolescents. For example, it is possible that the factors often thought to encourage materialism in children and adolescents, such as peer influence, actually yield their influence in an indirect manner-by affecting self-esteem. Third, our findings have implications for reducing the level of materialism often seen among early adolescents and even late adolescents. Our results indicate that simple actions to raise self-esteem among young consumers can have a dramatic impact on expressions of materialism.

\section{CONCEPTUAL OVERVIEW}

\section{What Is Materialism?}

Consumer researchers define materialism as "the importance a consumer attaches to worldly possessions" (Belk 1984, 291) and "the importance a person places on possessions and their acquisition as a necessary or desirable form of conduct to reach desired end states, including happiness" (Richins and Dawson 1992, 307). Although the accumulation of material possessions can be an end in itself, we are interested in the acquisition of material possessions as a means for achieving higher goals, such as self-definition and selfenhancement. Research conducted across a variety of disciplines-including psychology, sociology, and marketing-finds that many of the reasons for valuing possessions are related to expressing, maintaining, and signaling one's self-concept to others (Belk 1985; Czikszentmihalyi and Rochberg-Halton 1981; Holman 1981; Mukerji 1983; Solomon 1983). Another important goal is the pursuit of happiness. For example, Richins and Dawson (1992, 304) state that "it is the pursuit of happiness through acquisition rather than through other means (such as personal relationships, experiences, or achievements) that distinguishes materialism."

\section{What Role Does Self-Esteem Play in Materialism?}

One of the most consistent findings in the adult consumer behavior literature is the link between materialism and selfesteem, with lower feelings of self-worth related to higher 
levels of materialism (Mick 1996; Richins and Dawson 1992). Materialists are viewed as being caught in an endless cycle of acquiring material goods in hopes of compensating for feelings of insecurity and searching for happiness (Fournier and Richins 1991; Mick 1996; Richins and Dawson 1992). Psychological research also identifies feelings of insecurity and low self-esteem as important causes of materialism. Particularly germane to our discussion is the recent work of Tim Kasser and his colleagues, who argue that one way materialistic values develop is from "experiences that induce feelings of insecurity" (Kasser et al. 2004, 13). Consistent with this view, researchers have reported experimental evidence showing that induced feelings of insecurity and low self-esteem have a direct causal influence on materialistic orientations (Braun and Wicklund 1989; Chang and Arkin 2002; Kasser 2002; Solberg, Diener, and Robinson 2004).

Why does insecurity and low self-esteem lead to a materialistic orientation? Most researchers believe that material goods are an instrument for individuals to cope with or compensate for doubts about their safety, competence, and self-worth (Chang and Arkin 2002; Kasser 2002). For example, Solomon (1983) explains that uncertainty makes individuals reliant upon the use of appropriate products as props to bolster their self-concepts. He provides the example of adolescent boys' use of "macho" products such as cars, clothing, and cologne to bolster their fragile masculine selfconcepts. Similarly, Brown, Collins, and Schmidt (1988) have proposed that individuals with low self-esteem engage in indirect self-enhancement by attaching themselves to people and material things that are perceived as having significant value.

\section{How Does Materialism Develop in Children and Adolescents?}

The desire for material goods begins at an early age. Toddlers and preschoolers make frequent requests for certain products and make their desires known in many ways, including grabbing products off store shelves, begging, and whining (John 1999). Children's drive to acquire these goods can be very strong, with an immediate and overwhelming desire for items such as toys, cereal, and candy (Goldberg and Gorn 1978). However, for young children, the acquisition of desired items is usually an end in itself rather than being a means for achieving higher-order goals, such as self-enhancement, usually associated with materialism.

When does this drive for material goods emerge? And how does it develop throughout childhood into adolescence? Although many aspects of development take place during childhood and adolescence, we begin our exploration with developments in self-esteem. Because materialism research with adults has identified a strong relationship between selfesteem and materialism, we use findings on children's developing self-esteem as a logical starting point for our discussion. We do, however, incorporate additional aspects of development into the discussion to explain why the link between self-esteem and material goods is particularly strong at certain ages.

Self-Esteem. In children and adolescents, self-esteem exhibits a strong age-related pattern. Self-esteem often declines around age 12 or 13 (Erikson 1963; Harter 1983; Mendelson and White 1985; Rosenberg 1979) and rebounds by middle to late adolescence (McCarthy and Hoge 1982; O'Malley and Bachman 1983). The decline in self-esteem from middle childhood to early adolescence has been explained by several factors, including physical changes accompanying puberty that make children very critical and self-conscious, discrepancies between an ideal self and how they see themselves, and moving into junior high schools where they are the youngest and least important members of the school (Simmons, Rosenberg, and Rosenberg 1973; Zigler, Balla, and Watson 1972). Self-esteem rebounds once adolescents become more realistic about their self-concept, more comfortable with their social environment and peer groups, and less self-conscious about their physical appearance (McCarthy and Hoge 1982).

Self-Esteem and Materialism. We know from the adult literature that material possessions provide a way to cope with insecurity and feelings of low self-esteem (Braun and Wicklund 1989; Chang and Arkin 2002; Kasser 2002; Solberg et al. 2004). But, can we expect children and adolescents to use material possessions in the same way? Using material possessions as a coping strategy for low self-esteem requires an understanding of the symbolic meanings of material goods and their usefulness for enhancing and communicating one's self-concept. That is, one needs to understand that material possessions have symbolic meanings, reflecting concepts such as prestige or sophistication, which can be used to cope with feelings of low self-worth and even communicate a more positive self-concept to others.

Understanding of these concepts develops during middle to late childhood. By the time children reach late childhood (ages 10-11), they understand symbolic meanings and status accorded to certain types of possessions and products, as reported in studies of the development of consumption symbolism (Belk, Bahn, and Mayer 1982; Belk, Mayer, and Driscoll 1984) and brand images (Achenreiner and John 2003; Chaplin and John 2005). Also by late childhood, children appreciate possessions as a way to define their selfconcepts, viewing possessions as a salient part of who they are (Chaplin and John 2005; Dixon and Street 1975). Added to this is a new understanding of how they are perceived by others (Selman 1980) and that impressions are formed on the basis of many factors (Barenboim 1981), including ownership of material goods (Chaplin and John 2005).

This new appreciation for material possessions emerges about the same time as children experience a decline in selfesteem as they enter adolescence (ages 12-13), providing a strong motivation for acquiring possessions to enhance their self-esteem, thereby fueling materialistic tendencies. Consistent with this view, researchers have explained that ad- 
olescents manage their impressions by acquiring brands and products used by their peer group such as clothing, music, and even cigarettes, using them as props to seek peer acceptance (Cohen 1982; Solomon 1983).

By late adolescence (ages 16-18), self-esteem begins to rebound and the emphasis on material possessions is lessened. As older adolescents become more realistic about their self-concept and more comfortable with their social environment, the need for coping strategies to overcome feelings of low self-worth becomes less urgent (McCarthy and Hoge 1982). Additionally, older adolescents have a fuller repertoire of strategies for bolstering their feelings of self-worth and managing the impressions they communicate to others. By late adolescence, individuals gain more personal autonomy and freedom of action to behave in ways that are more effective in enhancing their self-esteem (McCarthy and Hoge 1982), such as choosing their own social groups and placing more emphasis on activities and accomplishments than on material goods for self-definition (Belk 1988).

Hypotheses. By the time children reach early adolescence and experience a decline in self-esteem, the stage is set for the use of material possessions as a coping strategy for feelings of low self-worth. This leads to a focus on material goods as an indirect means of self-enhancement and the adoption of materialistic tendencies. In contrast, the increase in self-esteem occurring between early and late adolescence results in a decrease in materialism as adolescents develop a more confident sense of who they are and develop means of self-enhancement that do not rely solely on material possessions. Hence, we predict:

H1: Age differences in materialism exist among children and adolescents.

H1a: Early adolescents (ages 12-13) are more materialistic than younger children (ages 8-9).

H1b: Late adolescents (ages 16-18) are less materialistic than early adolescents (ages 12-13).

H2: Age differences in materialism are mediated by self-esteem.

H2a: Early adolescents (ages 12-13) are more materialistic than younger children (ages 8-9) due to lower self-esteem.

H2b: Late adolescents (ages 16-18) are less materialistic than early adolescents (ages 12-13) due to higher self-esteem.

\section{STUDY 1}

\section{Sample}

Participants from three age groups were recruited from St. Paul, Minnesota: 50 third/fourth graders (ages 8-9), 50 seventh/eighth graders (ages 12-13), and 50 eleventh/ twelfth graders (ages 16-18). Each age group contained an equal number of males and females. Parental consent and participant assent were obtained prior to the study.

\section{Procedure}

Participants were interviewed individually. After a brief description of the study, respondents completed tasks measuring their level of materialism and then self-esteem. Each task was described and demonstrated by the interviewer. Next, participants completed several questions used for measure validation. Participants were then debriefed, asked not to talk about the study until its completion, and compensated with small prizes for their participation. The procedure took approximately 45 minutes to complete.

\section{Measures}

Self-Esteem. Self-esteem was measured using a sorting task. To begin, the experimenter placed four $3 \times 5$ index cards in front of the child, with individual cards labeled "all of the time," "most of the time," "sometimes," and "never." Participants were handed a deck of $3 \times 5$ index cards, with each card containing an item adapted from Rosenberg's (1965) self-esteem scale (see table 1). Participants read each item and decided how often it described them (all of the time, most of the time, sometimes, or never). A child who felt that this statement described him/her all of the time, would take that card and place it in the pile labeled "all of the time." The same procedure was used for all 20 items, and responses were summed to obtain the final measure.

Materialism. Materialism was measured by asking participants to construct a collage to answer the question, "What makes me happy?" Choosing more material goods, such as "money" and "brand names," over nonmaterialistic sentiments, such as "being with friends" or "no homework," indicated higher levels of materialism. Although rating scales are often used to measure materialism in adults, we selected a collage format to accommodate the wide age range (8-18 years) in our sample, which is broader than age ranges included in prior work using rating scales (e.g., 9-14 years; Goldberg et al. 2003). Rating scales ask respondents to agree or disagree with statements such as "Money can buy happiness," which can have a different meaning for young children versus older adolescents and adults. However, the basic concept of "happiness" is easy to understand regardless of age. Combining the basic concept of "happiness" with a collage methodology, which has been successfully used with children and adolescents (Chaplin and John 2005), produced a task that was familiar, engaging, and well understood by the wide age range of respondents in our study. Also, by measuring materialism in a less transparent way than rating scales, we hoped to reduce socially desirable responding among older adolescents, who are quite aware of negative connotations attached to materialistic values.

The collage exercise began by showing participants a set of stimuli available for composing their collages. Although collage methods often require respondents to find their own 
TABLE 1

STUDY 1: MEASUREMENT SCALES

\begin{tabular}{|c|c|c|c|c|}
\hline Measure & Number of items & Examples & Response scale & $\begin{array}{c}\text { Reliability } \\
\text { (coefficient } \alpha \text { ) }\end{array}$ \\
\hline \multicolumn{5}{|l|}{ Main study measures: } \\
\hline Self-esteem & 20 & $\begin{array}{l}\text { "I feel good about myself" } \\
\text { "I am happy with the way I look" } \\
\text { "I'm just as good as anyone else" }\end{array}$ & $\begin{array}{l}4=\text { all the time } \\
3=\text { most of the time } \\
2=\text { sometimes } \\
1=\text { never }\end{array}$ & .86 \\
\hline \multirow{2}{*}{$\begin{array}{l}\text { Validation measures: } \\
\text { Youth Materialism Scale } \\
\text { (YMS) }\end{array}$} & & & & \\
\hline & 10 & $\begin{array}{l}\text { "I would love to buy things that } \\
\text { cost lots of money" } \\
\text { "When you grow up, the more } \\
\text { money you have the happier } \\
\text { you'll be" }\end{array}$ & $\begin{array}{l}4=\text { YES } \\
3=\text { yes } \\
2=\text { no } \\
1=\text { NO }\end{array}$ & .78 \\
\hline Selfishness & 6 & $\begin{array}{l}\text { "My happiness depends on the } \\
\text { happiness of those around me" } \\
\text { "I try to do what is best for me, } \\
\text { regardless of how that might } \\
\text { affect others" }\end{array}$ & $\begin{array}{l}4=\text { all the time } \\
3=\text { most of the time } \\
2=\text { sometimes } \\
1=\text { never }\end{array}$ & .83 \\
\hline Impression management & 5 & $\begin{array}{l}\text { "In order to get along and be } \\
\text { liked, I am what people expect } \\
\text { me to be" } \\
\text { "I can change my behavior de- } \\
\text { pending on who is around" }\end{array}$ & $\begin{array}{l}4=\text { all the time } \\
3=\text { most of the time } \\
2=\text { sometimes } \\
1=\text { never }\end{array}$ & .71 \\
\hline
\end{tabular}

pictures or words, we provided a set of stimuli to ensure that younger as well as older respondents would have an accessible set of materials. These items were mounted on five poster boards, each representing a different theme: hobbies, people, sports, material things, and achievements (see fig. 1). These themes were suggested by pilot tests asking children and adolescents to answer an open-ended question about happiness ("What makes you happy?). Twenty laminated labels and/or pictures were placed on each board. For example, "camping" and "skateboarding" labels were included on the hobbies board, "getting good grades" and "being good at sports" were found on the achievements board, "money" and "new clothes" were included on the material things board, "basketball" and "hockey" were pictured on the sports board, and "friends" and "teacher" were included on the people board. These items were selected to appeal to a wide range of interests. For example, for material things, we selected many popular items across age groups (e.g., money), a few more popular with younger children (e.g., stuffed animals), a few more popular with older children (e.g., nice car), a few more popular with boys (e.g., nice sports equipment), and a few more popular with girls (e.g., jewelry).

Participants were asked to construct their happiness collage by choosing items from the theme boards. Post-it boards, the size of a poster board covered with a repositionable adhesive, were used for the theme boards and blank collage board. This allowed participants to easily move pictures and labels from board to board, add or eliminate labels from collages, and artistically arrange the elements on their collage. Blank cards and markers were available for partic- ipants to make up their own labels or pictures. Upon completing their collages, participants were asked to describe why they had placed certain items on the collage. These responses served as a check to ensure that collage items were being interpreted as material goods or nonmaterial goods as we intended. A photograph of the collage was then taken for later data analysis.

Next, we asked participants to reduce their collages by discarding half of the labels or pictures, leaving the items most important to their happiness. Participants were forced to make trade-offs at this stage, which encouraged participants to think carefully about the things that truly made them happy versus things that were not crucially important to their happiness. A photograph of the happiness collage (now in its reduced form) was taken for data analysis.

Two measures of materialism were computed from each child's original and reduced happiness collage (see fig. 2). The first measure was the number of material possessions included on the collage. A second measure adjusted for the possibility that a larger number of material items might be included on the collage simply because of a greater number of items on a collage. We adjusted for collage size by dividing the number of material possessions on a collage by the total number of items on the collage.

\section{Results}

Reliability and Validity. We conducted several analyses for the materialism collage measures. For test-retest reliability, we asked a sample of respondents to complete a second happiness collage two weeks after the main study. 
FIGURE 1

THEME BOARD EXAMPLES

\section{A. Sports}

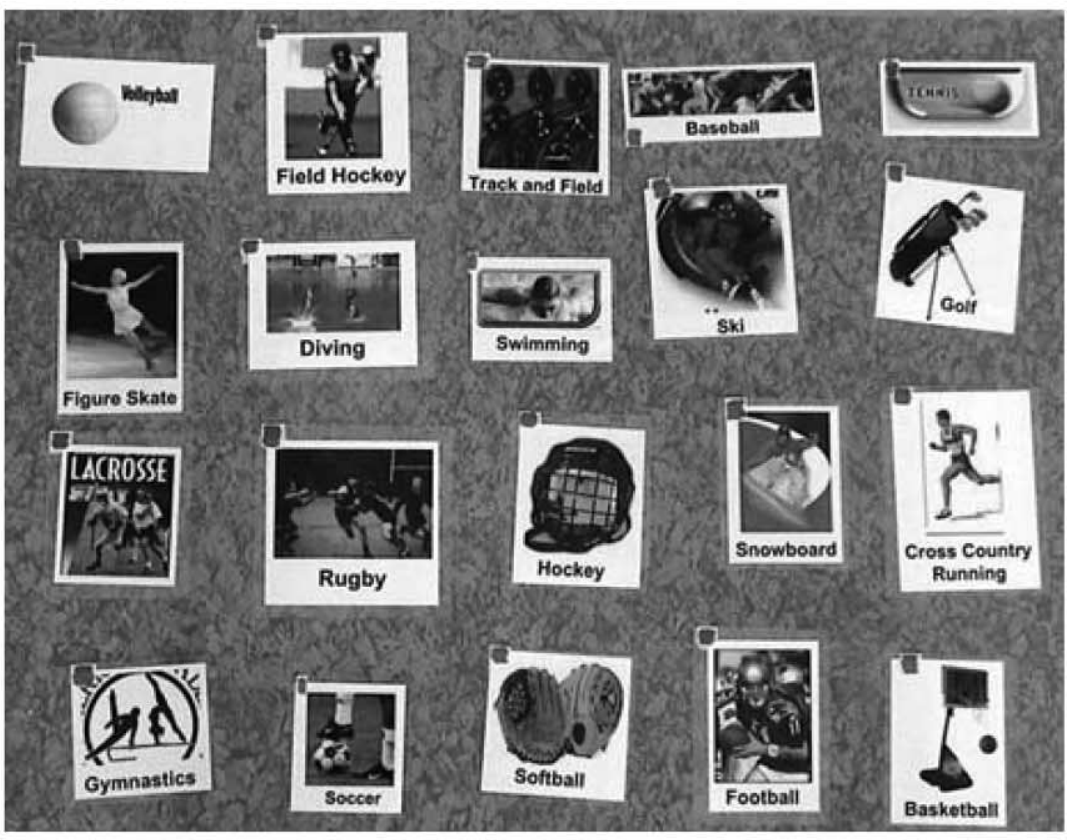

B. Material Things

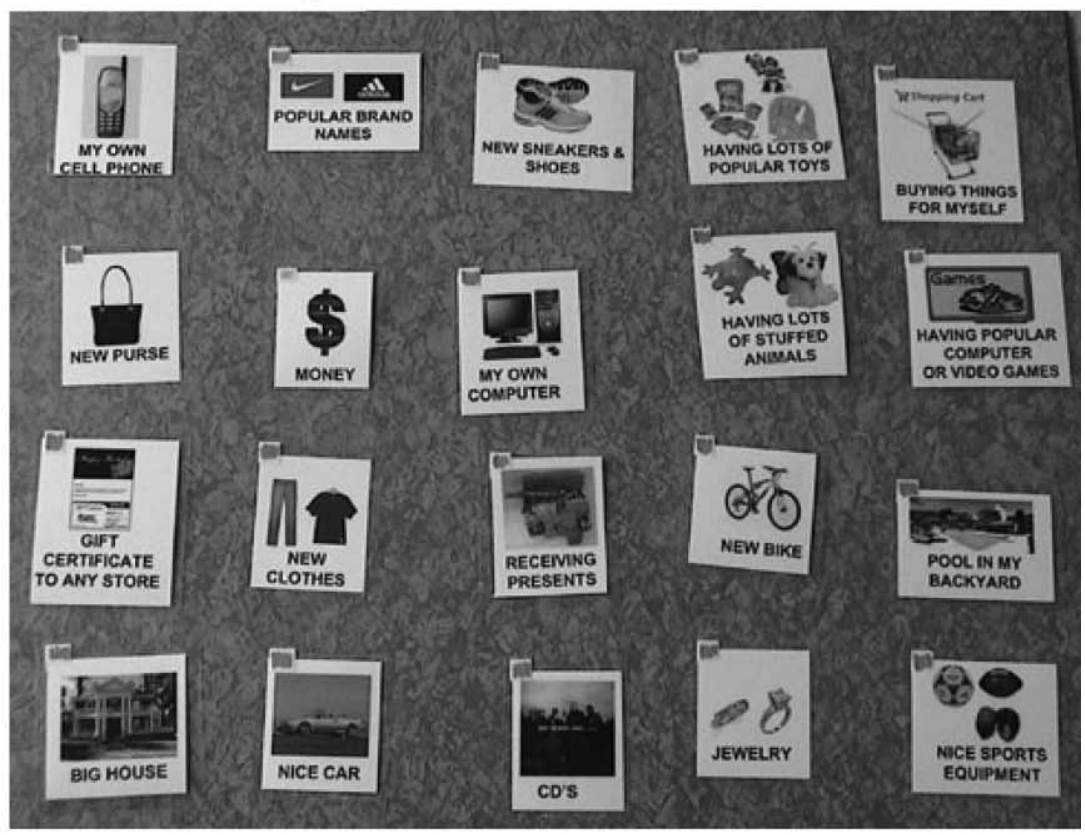

Comparing these collages to those from the main study, we found strong test-retest correlations for the number of material possessions (original collage: $r=.84, p<.01$; reduced collage: $r=.88, p<.01)$ and the percentage of ma- terial possessions (original collage: $r=.87, p<.01$; reduced collage: $r=.89, p<.01)$.

Tests of concurrent validity were also conducted. Materialism measures based on the original collage were corre- 


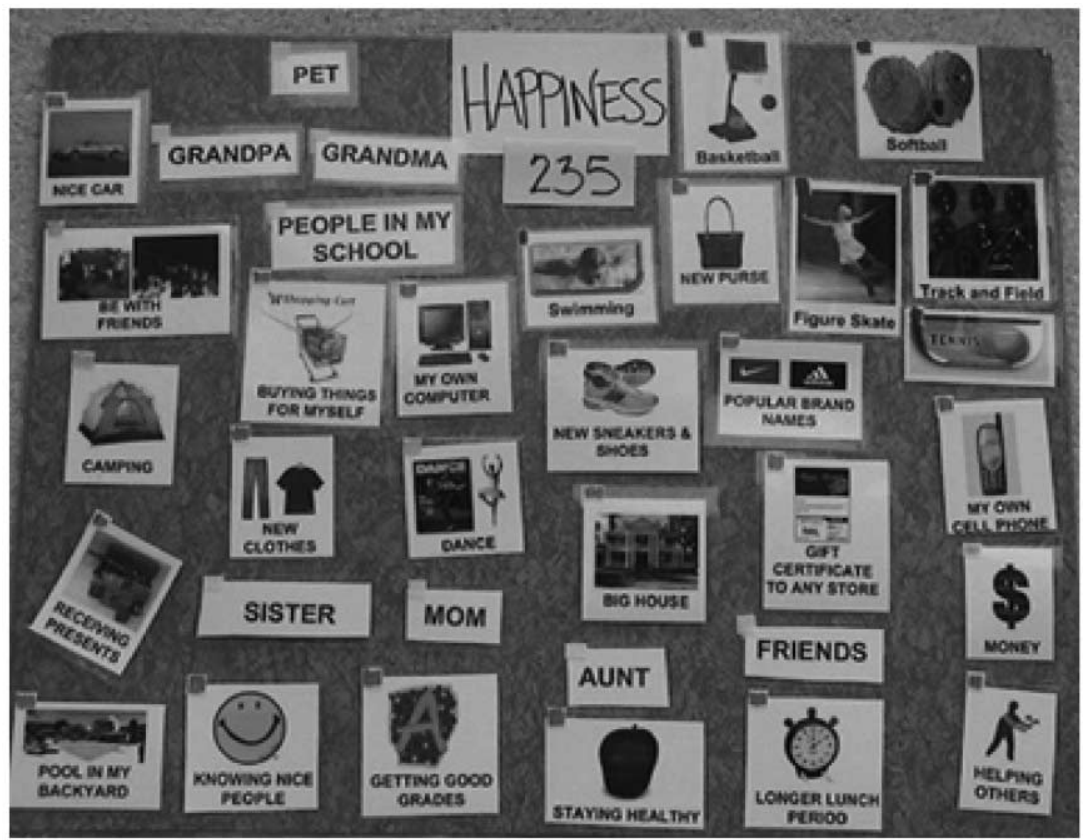

lated with those for the reduced collage, indicating strong concurrent validity for the number of material possessions $(r=.71, p<.01)$ and the percentage of material possessions $(r=.67, p<.01)$. Given these results, we focused attention on measures from the original collage, specifically the number of material possessions, for subsequent analyses.

We also correlated our measure with Goldberg et al.'s (2003) Youth Materialism Scale (YMS), the best rating scale available for measuring materialism in children 9-14 years of age. The YMS asks children to agree or disagree with a series of statements that reflect materialistic values, including two items referring to possessions as a means for achieving happiness (see table 1). We made one modification to the scale, using scale points of "YES, yes, no, NO" in lieu of "agree" and "disagree," to make it easier for our youngest respondents. For validation purposes, we correlated the YMS and happiness collage measures for 9-14-year-olds in our sample. Although these two measures are different in nature, we expected, and found, a high correlation between the two measures $(r=.88, p<.01)$.

Third, we correlated our materialism measure with a measure of selfishness. Researchers have used measures of selfishness (nongenerosity) to validate materialism measures with adults (Richins and Dawson 1992). We asked participants to respond to six statements, which were summed to form a selfishness scale (see table 1). The resulting scale was correlated with our measure of materialism, confirming a significant positive correlation $(r=.53, p<.01)$.

Finally, to assess whether socially desirable responding (SDR) might be operative, we correlated our materialism measure with one measuring impression management (see table 1). Impression management has been identified as the most important aspect of socially desirable responding (Mick 1996), with evidence of SDR indicated by a significant negative correlation between materialism and impression management. However, we found a significant positive correlation between materialism and impression management ( $r=.42, p<.01)$, suggesting that SDR is not a factor. In fact, the positive correlation supports our view of materialism as instrumental to the purposes of selfenhancement.

Tests were also conducted for the self-esteem measure. A test of internal consistency indicated an acceptable level of reliability $(\alpha=.86)$. To validate children's responses, we identified camp counselors who had known each participant for at least a year. Counselors were asked to rate the self-esteem of the participant by agreeing or disagreeing with the statement, "In general, [name of participant] views him/herself favorably" on a 1 (disagree a lot) to 5 (agree a lot) scale. Correlations between children's and counselor's ratings indicated an acceptable level of convergence $(r=$ $.62, p<.01)$.

Hypothesis 1. Planned contrasts between age groups confirmed the existence of age differences in materialism (see fig. 3). Specifically, 8-9-year-olds included fewer material items on their collages than did 12-13-year-olds $(M=$ 3.62 vs. $6.72, t(1,98)=5.50, p<.01)$ and $16-18$-year-olds included fewer material items than did 12-13-year-olds $(M=5.26$ vs. $6.72, t(1,98)=2.38, p=.02)$. These age- 
FIGURE 3

STUDY 1: AGE DIFFERENCES IN SELF-ESTEEM AND MATERIALISM
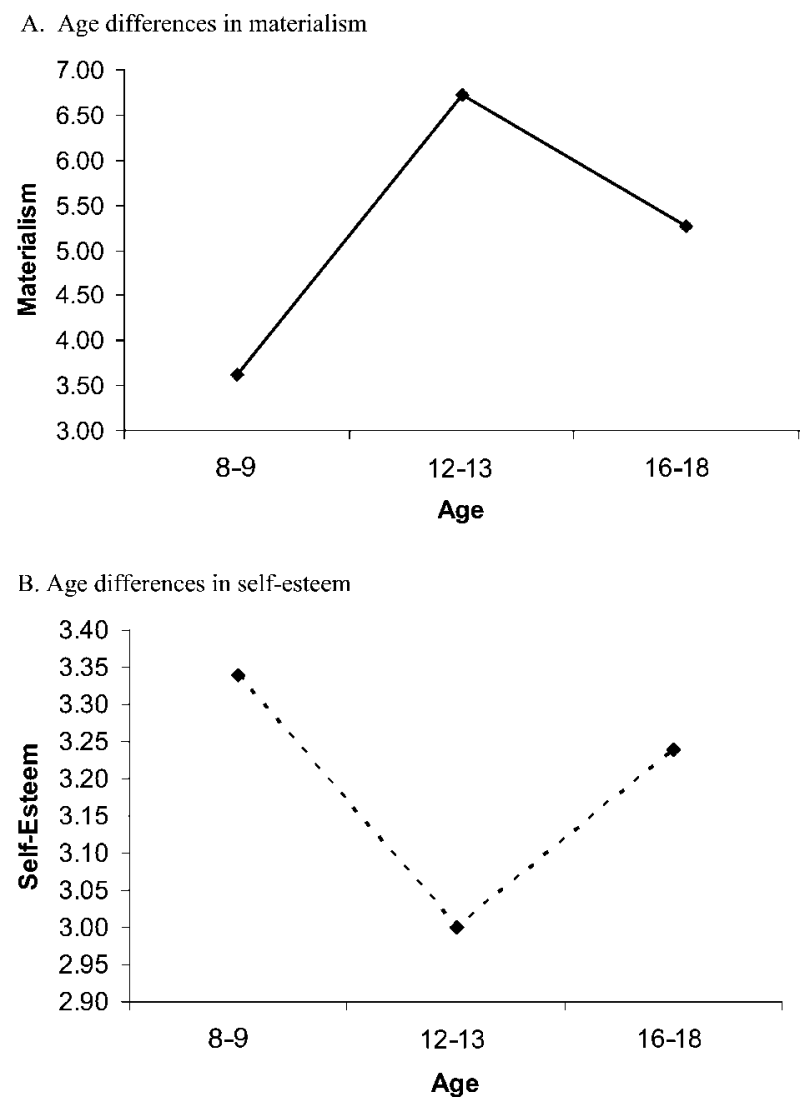

related trends were not influenced by collage size, indicated by an absence of age differences for total number of items placed on collages $\left(M_{\text {ages 8-9 }}=26.54, M_{\text {ages 12-13 }}=28.64\right.$, $M_{\text {ages 16-18 }}=27.98$, all $p$ 's $\left.>.15\right)$. Data from reduced collages exhibited the same trends, with 8-9-year-olds including fewer material things than did $12-13$-year-olds $(M=.90$ vs. 2.94, $t(1,98)=5.45, \quad p<.01)$ and 16-18-year-olds including fewer material items than did 12-13-year-olds $(M=1.38$ vs. 2.94, $t(1,98)=3.90, p<.01)$.

Hypothesis 2. The mediating role of self-esteem was examined using tests of mediation outlined by Baron and Kenny (1986). For each age contrast of interest, 8-9-yearolds versus 12-13-year-olds and 12-13-year-olds versus 16-18-year-olds, we specified three separate regressions: (1) the effect of age on materialism, (2) the effect of age on self-esteem, and (3) the effect of age and self-esteem on materialism. A mediating effect is supported if the coefficients for age in the first two equations and the coefficient for self-esteem in the third equation are significant and if the effect of age on materialism is weaker in the third regression than in the first. Perfect mediation is indicated if age has no effect with self-esteem included in the model.
Our analysis provided support for the mediating effect of self-esteem (see table 2). Results for the first two regressions indicate a significant effect of age on materialism as well as a significant effect of age on self-esteem. Thus, the expected age differences in self-esteem emerged. We found 8-9-year-olds had higher self-esteem than did 12-13-yearolds $(M=3.34$ vs. 3.00, $t(1,98)=4.30, p<.01)$ and 16-18-year-olds had higher self-esteem than did 12-13year-olds $(M=3.24$ vs. $3.00, t(1,98)=2.87, p=.01)$. Results for the third regression yielded evidence of selfesteem as a mediator of the relationship between age and materialism. Specifically, self-esteem is a partial mediator for the increase we see in materialism from middle childhood (ages 8-9) to early adolescence (ages 12-13), indicated by a drop in the size of the age coefficient from the first to third regression. Self-esteem is a perfect mediator for the decrease we see in materialism from early adolescence (ages 12-13) to late adolescence (ages 16-18), indicated by a drop in the significance of the age coefficient from the first to third regression.

\section{Discussion}

The results of this study confirm the existence of age differences in materialism. We found materialism increasing from middle childhood to early adolescence and then decreasing by late adolescence. These patterns are related to levels of self-esteem. Decreases in self-esteem occurring between middle childhood and early adolescence appear to result in increases in materialism. As self-esteem rebounds from early to late adolescence, we see decreases in materialism. Self-esteem is not only related to materialism $(r=-.37, p<.01)$ but also a mediator of the relationship between age and materialism.

These results need to be considered in light of the usual questions raised by correlational data. One concern is that reported correlations between two variables can be spurious in nature, emerging only because both are related to a third variable. For example, age and materialism might be correlated only because they are both independently related to the amount of spending money that a child or adolescent receives from their parents or a job. Or self-esteem might be correlated to materialism only because both of these factors are related to age. A second concern is that correlation does not imply causation. Although this is not an issue for some of the relationships we report, notably between age and materialism or age and self-esteem, it is a concern for the relationship between self-esteem and materialism. The possibility exists that low self-esteem may be a consequence, rather than a cause, of materialism.

We address these concerns by examining the causal link between age, self-esteem, and materialism in a second study. We adopt an experimental approach used by psychologists to study the link between concepts such as insecurity or selfworth and materialism (Chang and Arkin 2002; Kasser 2002; Solberg et al. 2004). Although individuals exhibit chronic levels of self-esteem and materialism, levels of self-esteem and expressions of materialism can vary by situation (Chang 
TABLE 2

STUDY 1: MEDIATING EFFECTS OF SELF-ESTEEM

\begin{tabular}{|c|c|c|c|c|c|}
\hline Dependent variable & Independent variable & Coefficient & $p$-value & $F$-value & $R^{2}$ \\
\hline \multicolumn{6}{|l|}{ Materialism } \\
\hline \multicolumn{6}{|l|}{ Regression 1: } \\
\hline Materialism & Age1 & .47 & .000 & 28.041 & .222 \\
\hline \multicolumn{6}{|l|}{ Regression 2: } \\
\hline Self-esteem & Age1 & -.33 & .000 & 12.072 & .110 \\
\hline \multicolumn{6}{|l|}{ Regression 3: } \\
\hline \multirow[t]{2}{*}{ Materialism } & Age1 & .40 & .000 & 17.695 & .267 \\
\hline & Self-esteem & -.22 & .017 & & \\
\hline \multicolumn{6}{|l|}{ Materialism } \\
\hline \multicolumn{6}{|l|}{ Regression 1: } \\
\hline Materialism & Age2 & -.26 & .009 & 7.106 & .068 \\
\hline \multicolumn{6}{|l|}{ Regression 2: } \\
\hline Self-esteem & Age2 & .27 & .007 & 7.598 & .072 \\
\hline \multicolumn{6}{|l|}{ Regression 3: } \\
\hline Materialism & Age2 & -.18 & .072 & 9.136 & .159 \\
\hline & Self-esteem & -.31 & .002 & & \\
\hline
\end{tabular}

NOTE.-Age1 indicates results for younger age groups (8-9-year-olds and 12-13-year-olds). Age2 indicates results for older age groups (12-13-year-olds and 16-18-year-olds).

and Arkin 2002). Thus self-esteem or self-worth can be manipulated, allowing one to observe the resulting changes in expressions of materialism.

In study 2, we manipulate self-esteem, which allows us to look at the causal influence of changing levels of selfesteem, with all other factors held constant. We prime high self-esteem and expect to see lower levels of materialism expressed by children and adolescents as compared to a control group. Specifically:

H3: Children/adolescents with induced feelings of high self-esteem will express lower levels of materialism than children/adolescents in the control group (no self-esteem prime).

\section{STUDY 2}

\section{Design, Sample, and Procedure}

We tested our predictions in a 2 (self-esteem prime: high, control) $\times 3$ (age: $8-9,12-13,16-18)$ between subjects design. Participants from three age groups were recruited from summer recreational and martial arts classes in UrbanaChampaign, Illinois: 35 third/fourth graders (ages 8-9; 17 girls and 18 boys), 35 seventh/eighth graders (ages 12-13; 18 girls and 17 boys), and 35 eleventh/twelfth graders (ages 16-18; 18 girls and 17 boys). Data for the experimental group were collected first, followed by the control group. Parental consent and participant assent were obtained prior to the study.

The procedure was identical to study 1 , with the exception of the self-esteem prime, which was administered to the experimental group at the beginning of the study. Participants completed the same tasks used in study 1 to measure self-esteem and materialism. In this study, the self-esteem measure was used as a manipulation check to assess the effectiveness of the self-esteem prime. The materialism measure, derived from the collage task, constituted the main dependent measure for this study.

\section{Self-Esteem Prime}

We primed self-esteem in the context of an activity, often used in schools and camps, asking children to write nice things about their fellow students or campers on paper plates. Upon completion, each child receives a paper plate with positive peer feedback about them (e.g., cool, pretty, funny). We used this activity to produce for participants in the experimental group a paper plate ("Nice Things about Me" plate) that had exactly eight items, half provided by fellow classmates/campers and half provided by camp counselors and class instructors.

In the high self-esteem prime condition, participants received their paper plate with the positive comments prior to the start of the study. As soon as they received their plate, they were asked to sit at a table, read their paper plate, and wait for the experimenter to complete paperwork needed to begin the study. At the table, in clear view of the participant, were five additional "Nice Things about Me" plates belonging to other children, with each plate having only three positive comments (see fig. 4). These plates were made by the experimenter as props for the study and did not belong to fellow classmates or campers. Participants were able to see that the other children's plates had only three nice descriptions, while theirs had many more.

In the control condition, participants also received a "Nice Things about Me" plate, but they were given the plate at the completion of the study. Thus, respondents completed a happiness collage before receiving their "Nice Things about Me" plate. The purpose of the "Nice Things about Me" plate for the control group was simply to make sure that all participants in the study had a plate to take home 
FIGURE 4

STUDY 2: HIGH SELF-ESTEEM PRIME
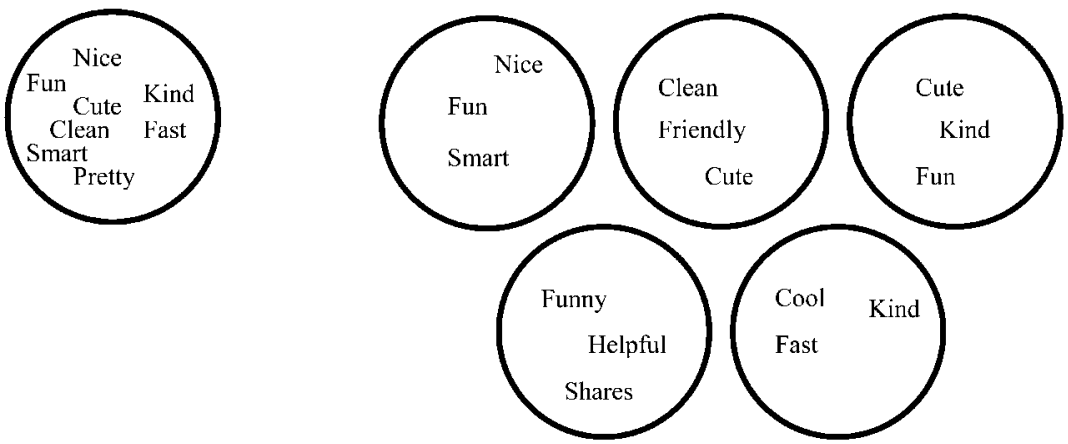

with them at the end of the study, regardless of the condition to which they were assigned.

\section{Results}

Self-Esteem. A 2 (self-esteem prime: high, control) $\times$ 3 (age: 8-9, 12-13, 16-18) ANOVA was performed on the self-esteem measure (see table 3 for means and standard deviations). The results confirmed the success of the selfesteem prime. A significant main effect of the self-esteem prime emerged $(F(1,99)=65.40, p<.01)$, with participants in the control condition reporting lower self-esteem $(M=2.93)$ than participants in the high self-esteem prime condition $(M=3.48)$. Contrasts performed for each age group confirmed that the self-esteem prime was successful for 8-9-year-olds $(t(1,33)=2.69, p<.01), 12-13$-yearolds $(t(1,33)=5.25, \quad p<.01)$, and 16-18-year-olds $(t(1,33)=7.92, p<.01)$. As expected, the impact of the self-esteem prime on reported self-esteem was similar across age levels, as indicated by the absence of a significant age $\times$ self-esteem prime interaction $(p>.10)$.

Materialism. A 2 (self-esteem prime: high, control) $\times$ 3 (age: 8-9, 12-13, 16-18) ANOVA was performed on the materialism measure (see table 3 for means and standard deviations). As predicted, a significant main effect of the selfesteem prime emerged $(F(1,99)=69.34, p<.01)$. Participants in the high self-esteem prime condition were less materialistic than those in the control condition $(M=2.84$ vs. 6.00). Contrasts performed for each age group confirmed that the self-esteem prime had a significant effect on materialism for $8-9$-year-olds $(M=4.30$ vs. 3.27, $t(1,33)=$ 2.47, $p=.05), \quad 12-13$-year-olds $(M=8.00$ vs. 2.93, $t(1,33)=59.46, p<.01)$, and 16-18-year-olds $(M=5.70$ vs. $2.33, t(1,33)=26.26, p<.01)$.

Interestingly, the self-esteem main effect was qualified by a significant age $\times$ self-esteem prime interaction $(F(2,99)=9.52, p<.01)$. As predicted, materialism was higher for the control group versus the high self-esteem prime group for each age group. However, the self-esteem prime had a much larger impact on expressions of materialism for the two older age groups, especially the 12-13-year-olds (see fig. 5). This finding is consistent with our theorizing in that early adolescents experience a large drop in self-esteem that leads to materialism; therefore, the boost in self-esteem they receive from our self-esteem prime has a very large impact on their expressions of materialism. In fact, the two older age groups benefit so much that there is an absence of age differences among participants in the high selfesteem condition (for all age contrasts, $p$ 's $>.15$ ). The curvilinear trend for age differences found in study 1 is still intact in the control condition, with materialism increasing from middle childhood to early adolescence $\left(M_{\text {ages 8-9 }}=\right.$ 4.30 vs. $\left.M_{\text {ages 12-13 }}=8.00, t(1,38)=37.00, p<.01\right)$ and decreasing from early adolescence to late adolescence $\left(M_{\text {ages 12-13 }}=8.00\right.$ vs. $M_{\text {ages 16-18 }}=5.70, t(1,38)=14.30$, $p<.01)$. Thus, priming high self-esteem eliminated age differences in materialism.

\section{Discussion}

The results of this study provide further support for the connection between self-esteem and materialism in children and adolescents. By priming higher levels of self-esteem, we were able to provide evidence of the causal role that self-esteem plays in fostering materialistic orientations. Materialism was higher for participants in the control condition than for those in the high self-esteem prime condition, for all three age groups. Our findings suggest that, over time, children who experience chronically high (low) levels of self-esteem are more likely to express lower (higher) levels of materialism.

Further, our results show that priming high self-esteem eliminates age differences in materialism, consistent with our conceptual story regarding self-esteem and materialism. 
We hypothesized that materialism increases as children approach early adolescence due to a severe drop in self-esteem that occurs around ages 12-13. By priming high self-esteem, we reversed the large drop in self-esteem experienced by early adolescents, thereby reducing the steep rise in materialism among this group.

\section{GENERAL DISCUSSION}

Our results document the existence of age differences in materialism. We find that materialism increases from middle childhood to early adolescence and declines from early to late adolescence (study 1). We also find that self-esteem is an important mediator of age differences (study 1) and that self-esteem is a significant cause of changes in expressions of materialism (study 2). Our results show that increases in self-esteem lead to lower levels of materialism.

\section{Theoretical Contributions}

Although many observers believe that children begin to exhibit materialistic orientations as they approach adolescence, there has been little empirical evidence to support the existence of age differences in materialism. Our findings support the idea that materialism develops as children enter adolescence but also point to a surprising downturn in materialism as children enter later adolescence. Most observers have focused on the increase in materialistic orientation that occurs with the onset of adolescence, but our research shows an equally interesting phenomenon of materialism decreasing as adolescents approach adulthood.

What accounts for age differences in materialism? We begin to address this question by focusing on the role that self-esteem plays in developing a materialistic orientation. Our view is that a drop in self-esteem experienced by many children as they enter adolescence triggers a focus on material goods, primarily as a means of self-enhancement. As self-esteem rebounds in late adolescence, the need for selfenhancement of any sort, including the use of material goods, declines along with a decrease in materialistic orientation.

The link between self-esteem and materialism provides a starting point for understanding how other factors may contribute to the rise in materialism as children approach adolescence. Previous research has identified a number of fac-
FIGURE 5

STUDY 2: AGE $\times$ SELF-ESTEEM PRIME INTERACTION

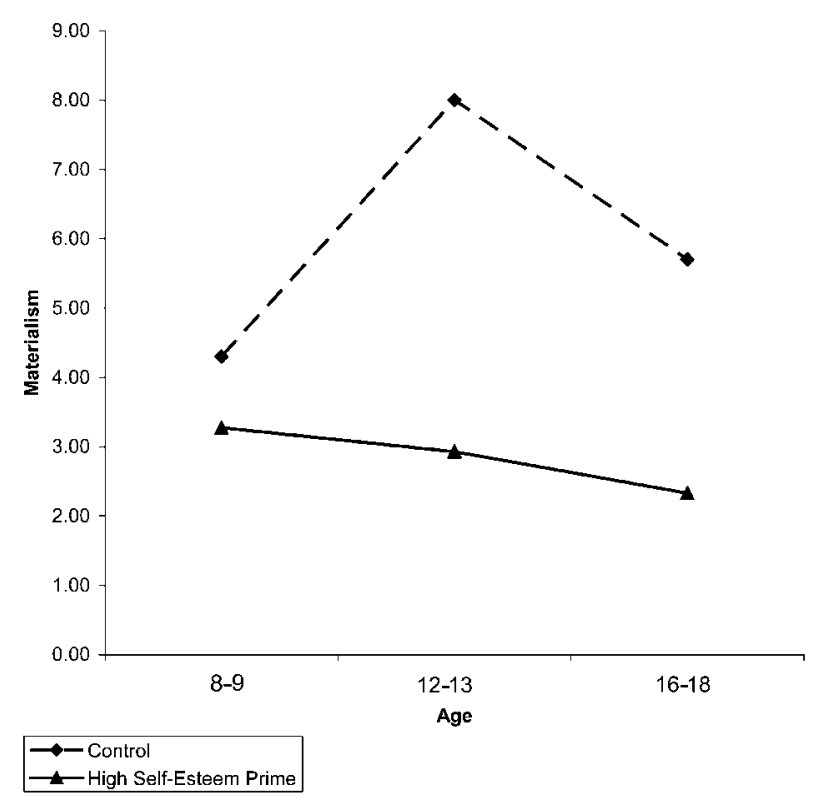

tors that are correlated with materialism in children and adolescents, such as family environment, parenting style, peer interaction, and media exposure. Although explanations have been forwarded for why each factor contributes to materialism, we propose that many of these factors influence materialism by affecting a child's level of self-esteem. Children who come from families with ineffective communication styles, with parents who do not provide a supportive atmosphere, and peers who exert too much influence in their lives are quite likely to experience low self-esteem. Children and adolescents are vulnerable to feelings of low self-esteem in these environments, leading to the search for something that will make them feel better about themselves. Material possessions fulfill this role for many children and adolescents, as they focus on material goods as a way to enhance their poor self-images.

To illustrate, consider the role of peer pressure in the development of materialistic orientations among adolescents. Peer pressure is often identified as an important factor

TABLE 3

STUDY 2: DESCRIPTIVE STATISTICS BY SELF-ESTEEM CONDITION

\begin{tabular}{|c|c|c|c|c|c|c|}
\hline & \multicolumn{3}{|c|}{ Control } & \multicolumn{3}{|c|}{ High self-esteem prime } \\
\hline & $\begin{array}{l}\text { Ages 8-9 } \\
(n=20)\end{array}$ & $\begin{array}{c}\text { Ages } 12-13 \\
(n=20)\end{array}$ & $\begin{array}{c}\text { Ages } 16-18 \\
(n=20)\end{array}$ & $\begin{array}{l}\text { Ages 8-9 } \\
(n=15)\end{array}$ & $\begin{array}{c}\text { Ages } 12-13 \\
(n=15)\end{array}$ & $\begin{array}{l}\text { Ages } 16-18 \\
(n=15)\end{array}$ \\
\hline Self-esteem & $\begin{array}{l}3.05 \\
(.38)\end{array}$ & $\begin{array}{l}2.70 \\
(.42)\end{array}$ & $\begin{array}{l}3.02 \\
(.24)\end{array}$ & $\begin{array}{l}3.40 \\
(.38)\end{array}$ & $\begin{array}{l}3.45 \\
(.41)\end{array}$ & $\begin{array}{l}3.60 \\
(.16)\end{array}$ \\
\hline Materialism & $\begin{array}{c}4.30 \\
(2.36)\end{array}$ & $\begin{array}{l}8.00 \\
(2.43)\end{array}$ & $\begin{array}{l}5.70 \\
(1.42)\end{array}$ & $\begin{array}{l}3.27 \\
(1.58)\end{array}$ & $\begin{array}{c}2.93 \\
(1.75)\end{array}$ & $\begin{array}{c}2.33 \\
(1.50)\end{array}$ \\
\hline
\end{tabular}

NOTE.-Numbers in parentheses represent standard deviations. 
that drives young people to acquire particular material goods in order to be accepted by their peers and escape ridicule. The influence of peers is thought to peak in early to mid adolescence (Berndt 1979), which is the same time frame we have isolated for a drop in self-esteem. We propose that self-esteem mediates the link between peer influence and materialism. We would also propose that self-esteem mediates the link between peer acceptance and materialism. These linkages can be tested, allowing us to build a conceptual framework to better understand how the many influences on materialism are related to each other in children and adolescents.

These possibilities could be tested in the context of a conceptual model similar to the one proposed by Kasser (Kasser 2002; Kasser et al. 2004). This model specifies that materialism develops through two paths: "(1) from experiences that induce feelings of insecurity and (2) from exposure to social models that encourage materialistic values" (Kasser et al. 2004, 13). A strong materialistic orientation is one way that individuals cope with or compensate for doubts about their safety, competence, and self-worth (path 1). People also become materialistic by internalizing the materialistic orientations of important people in their lives, such as parents or peers, and materialistic messages from popular culture and the media (path 2). Our results pertaining to self-esteem fit the first pathway well. Additional influences on materialism, including many addressed by prior research, may exert their effects in an indirect way through self-esteem (path 1) as we have suggested, and/or in a direct way through a modeling (path 2).

\section{Methodological Contributions}

One of the primary reasons why age differences in materialism have not received more attention is the difficulty of measuring materialism across a wide age range of children and adolescents. In this research, we use a collage methodology, which provides an engaging activity for young children and adolescents to reveal the importance of material goods in their lives. Collages have been used successfully in prior research with adults (Zaltman and Coulter 1995) as well as children (Chaplin and John 2005), providing several advantages over other methods. Collages involve less memory and verbalization than do in-depth interviews, while reducing comprehension demands for rating scales. These advantages are particularly important for measuring a concept as abstract as materialism with younger children. Our collage method also camouflages the intent of the measurement exercise, which is particularly important for older adolescents. By focusing the collage on the topic of happiness and providing a wide array of collage materials, we made it difficult to guess what was being measured, thereby reducing the opportunity to respond in a socially desirable manner.

Second, we introduce the use of experimental techniques into the study of materialism in children and adolescents. Experimental methods are becoming more frequent in psychological studies of materialism among adults (Braun and
Wicklund 1989; Kasser 2002; Solberg et al. 2004). Although these techniques have distinct benefits for researching adult populations, they are even more helpful in studying the causes of materialism among children and adolescents. For example, in studying age differences in materialism, one can easily identify a number of factors that change with age, such as advertising exposure, media use, product experience, product knowledge, and spending power. Experimental methods allow one to examine one or two factors of interest, such as self-esteem, holding all other possible factors constant.

\section{Societal Implications}

Questions about how materialism develops in children and adolescents are not only intriguing but are important to a wide range of constituents-parents, educators, public policy officials, and consumer researchers. Addressing these questions holds the promise of understanding more about materialism, about how values develop in our families and communities, and about how children become socialized as consumers in contemporary society.

For many constituents, the key question is what can be done to diminish materialism among children and adolescents? The ideas receiving the most attention appear to be those centered around placing constraints on media and advertising exposure - such as bans on advertising to children, bans on corporate marketing in public schools, and parental limits on TV exposure. Our results suggest that strategies aimed at increasing self-esteem among tweens and adolescents would be effective. In fact, we found a simple selfesteem manipulation to be so powerful among adolescents that it decreased their focus on material goods to the level of much younger children. Peer acceptance was the basis of our self-esteem manipulation, but there are many ways to influence feelings of self-worth and self-esteem in children and adolescents (Brooks and Goldstein 2001). Parents, teachers, peers, and other concerned adults can participate in this endeavor. Giving children or adolescents a sense of self-worth and accomplishment seems to be quite an effective antidote to the development of materialism.

\section{REFERENCES}

Achenreiner, Gwen Bachmann (1997), "Materialistic Values and Susceptibility to Influence in Children," in Advances in Consumer Research, Vol. 24, ed. Merrie Brucks and Deborah J. MacInnis, Provo, UT: Association for Consumer Research, 82-88.

Achenreiner, Gwen Bachmann and Deborah Roedder John (2003), "The Meaning of Brand Names to Children: A Developmental Investigation," Journal of Consumer Psychology, 13 (September), 205-19.

Barenboim, Carl (1981), "The Development of Person Perception in Childhood and Adolescence: From Behavioral Comparisons to Psychological Constructs to Psychological Comparisons," Child Development, 52 (March), 129-44.

Baron, Reuben M. and David A. Kenny (1986), "The Moderator- 
Mediator Variable Distinction in Social Psychological Research: Conceptual, Strategic, and Statistical Considerations," Journal of Personality and Social Psychology, 51 (December), $1173-82$.

Belk, Russell W. (1984), "Three Scales to Measure Constructs Related to Materialism: Reliability, Validity, and Relationships to Measures of Happiness," in Advances in Consumer Research, Vol. 11, ed. Thomas Kinnear, Provo, UT: Association for Consumer Research, 291-97.

- (1985), "Materialism: Trait Aspects of Living in the Material World," Journal of Consumer Research, 12 (December), 265-80.

- (1988), "Possessions and the Extended Self," Journal of Consumer Research, 15 (September), 139-68.

Belk, Russell W., Kenneth D. Bahn, and Robert N. Mayer (1982), "Developmental Recognition of Consumption Symbolism," Journal of Consumer Research, 9 (June), 4-17.

Belk, Russell W., Robert Mayer, and Amy Driscoll (1984), "Children's Recognition of Consumption Symbolism in Children's Products," Journal of Consumer Research, 10 (March), 386-97.

Berndt, Thomas (1979), "Developmental Changes in Conformity to Peers and Parents," Developmental Psychology, 15 (6), 608-16.

Braun, Ottmar L. and Robert Wicklund (1989), "Psychological Antecedents of Conspicuous Consumption," Journal of Economic Psychology, 10 (June), 161-87.

Brooks, Robert and Sam Goldstein (2001), Raising Resilient Children, Chicago: Contemporary Books.

Brown, Jonathan D., Rebecca L. Collins, and Greg W. Schmidt (1988), "Self-Esteem and Direct versus Indirect Forms of SelfEnhancement," Journal of Personality and Social Psychology, 55 (September), 445-53.

Center for a New American Dream (2004), New American Dream Survey Report, http://www.newdream.org/about/PollResults .pdf.

Chang, LinChiat and Robert M. Arkin (2002), "Materialism as an Attempt to Cope with Uncertainty," Psychology and Marketing, 19 (May), 389-406.

Chaplin, Lan Nguyen and Deborah Roedder John (2005), "The Development of Self-Brand Connections in Children and Adolescents," Journal of Consumer Research, 32 (June), 119-29.

Churchill, Gilbert A. and George P. Moschis (1979), "Television and Interpersonal Influences on Adolescent Consumer Learning," Journal of Consumer Research, 6 (June), 23-35.

Cohen, Joel B. (1982), "Playing to Win: Marketing and Public Policy at Odds over Joe Camel," Journal of Public Policy and Marketing, 19 (Fall), 155-67.

Czikszentmihalyi, Mihaly and Eugene Rochberg-Halton (1981), The Meaning of Things: Domestic Symbols of the Self, Cambridge: Cambridge University Press.

Dixon, James and Jeannie Street (1975), "The Distinction between Self and Not-Self in Children and Adolescents," Journal of Genetic Psychology, 127 (December), 157-62.

Erikson, Erik H. (1963), Childhood and Society, New York: Norton.

Fournier, Susan and Marsha L. Richins (1991), "Some Theoretical and Popular Notions Concerning Materialism," Journal of Social Behavior and Personality, 6 (6), 403-14.

Goldberg, Marvin E. and Gerald J. Gorn (1978), "Some Unintended Consequences of TV Advertising to Children," Journal of Consumer Research, 5 (June), 22-29.

Goldberg, Marvin E., Gerald J. Gorn, Laura A. Peracchio, and Gary Bamossy (2003), "Understanding Materialism among
Youth," Journal of Consumer Psychology, 13 (September), 278-88.

Harter, Susan (1983), "To Smile or Not to Smile: Issues in the Examination of Cross-Cultural Differences and Similarities," Monographs of the Society for Research in Child Development, 48 (5), 80-87.

Holman, Thomas B. (1981), "The Influence of Community Involvement on Marital Quality," Journal of Marriage and the Family, 43 (February), 143-49.

John, Deborah Roedder (1999), "Consumer Socialization of Children: A Retrospective Look at Twenty-Five Years of Research," Journal of Consumer Research, 26 (December), 183-213.

Kantrowitz, Barbara and Pat Wingert (1999), "The Truth about Tweens," Newsweek, October 18, 62-79.

Kasser, Tim (2002), The High Price of Materialism, Cambridge, MA: MIT Press.

Kasser, Tim, Richard M. Ryan, Charles E. Couchman, and Kennon M. Sheldon (2004), "Materialistic Values: Their Causes and Consequences," in Psychology and Consumer Culture, ed. Tim Kasser and Allen D. Kanner, Washington, DC: American Psychological Association, 11-28.

Lindstrom, Martin (2003), BRANDchild, London: Kogan Page.

Linn, Susan (2004), Consuming Kids: The Hostile Takeover of Childhood, New York: New Press.

McCarthy, John D. and Dean R. Hoge (1982), "Analysis of Age Effects in Longitudinal Studies of Adolescent Self-Esteem," Developmental Psychology, 18 (May), 372-79.

Mendelson, Beverly K. and Donna R. White (1985), "Development of Self-Body-Esteem in Overweight Children," Developmental Psychology, 21 (January), 90-96.

Mick, David Glen (1996), "Are Studies of Dark Side Variables Confounded by Socially Desirable Responding? The Case of Materialism," Journal of Consumer Research, 23 (September), 106-19.

Moore, Roy L. and George P. Moschis (1981), "The Role of Family Communication in Consumer Learning," Journal of Communications, 31 (Autumn), 42-51.

Moschis, George P. and Gilbert A. Churchill Jr. (1978), “Consumer Socialization: A Theoretical and Empirical Analysis," Journal of Marketing Research, 15 (November), 599-609.

Moschis, George P. and Roy Moore (1979), "Decision Making among the Young: A Socialization Perspective," Journal of Consumer Research, 6 (September), 101-12.

Mukerji, Chandra (1983), From Graven Images: Patterns of Modern Materialism, New York: Columbia University Press.

O'Malley, Patrick M. and Jerald G. Bachman (1983), "Self-Esteem: Change and Stability between Ages 13 and 23," Developmental Psychology, 19 (March), 257-68.

Quart, Alissa (2003), The Buying and Selling of Teenagers, Cambridge, MA: Perseus.

Richins, Marsha L. and Scott Dawson (1992), “A Consumer Values Orientation for Materialism and Its Measurement: Scale Development and Validation," Journal of Consumer Research, 19 (December), 303-16.

Rindfleisch, Aric, James E. Burroughs, and Frank Denton (1997), "Family Structure, Materialism, and Compulsive Consumption," Journal of Consumer Research, 23 (March), 312-25.

Roberts, James A., John F. Tanner, and Chris Manolis (2005), "Materialism and the Family Structure-Stress Relation," Journal of Consumer Psychology, 15 (2), 183-90.

Rosenberg, Morris (1965), Society and the Adolescent Self-Image, Princeton, NJ: Princeton University Press. 
(1979), Conceiving the Self, New York: Basic.

Schor, Juliet B. (2004), Born to Buy, New York: Scribner.

Selman, Robert L. (1980), The Growth of Interpersonal Understanding, New York: Academic.

Seyfer, Jessie (1999), "School Board Bans Ads in Textbooks, May Remove Some Snacks," Marketing News, 19 (July), 8.

Siegel, David L., Timothy J. Coffey, and Gregory Livingston (2001), The Great Tween Buying Machine, Ithaca, NY: Paramount Market.

Simmons, Roberta, Florence Rosenberg, and Morris Rosenberg (1973), "Disturbance in Self-Image at Adolescence," American Sociological Review, 38 (October), 553-68.

Solberg, Emily G., Edward Diener, and Michael D. Robinson (2004), "Why Are Materialists Less Satisfied?" in Psychology and Consumer Culture, ed. Tim Kasser and Allen D. Kanner,
Washington, DC: American Psychological Association, 29-48.

Solomon, Michael R. (1983), "The Role of Products as Social Stimuli: A Symbolic Interactionism Perspective," Journal of Consumer Research, 10 (December), 319-29.

Zaltman, Gerald and Robin Higie Coulter (1995), "Seeing the Voice of the Customer: Metaphor-Based Advertising Research," Journal of Advertising Research, 35 (July-August), $35-51$.

Zigler, Edward, David Balla, and Neill Watson (1972), "Developmental and Experiential Determinants of Self-Image Disparity in Institutionalized and Noninstitutionalized Retarded and Normal Children," Journal of Personality and Social Psychology, 23 (July), 81-87. 